\title{
Fuzzy control scheme for energy efficiency and demand management in airports using 3D simulator
}

\author{
Mohamed Abdul Raouf Shafei ${ }^{1}$, Mohamed Abdelazeem Tawfik ${ }^{2}$, Doaa Khalil Ibrahim ${ }^{3}$ \\ ${ }^{1,3}$ Electrical Power Engineering Department, Faculty of Engineering, Cairo University, Egypt \\ ${ }^{2}$ Egyptian Airports Company, Egypt
}

\section{Article Info \\ Article history: \\ Received Feb 12, 2020 \\ Revised Apr 10, 2020 \\ Accepted Apr 26, 2020}

\section{Keywords:}

3D simulator

Airports

Building management system

Energy efficiency

Fuzzy logic control

\begin{abstract}
As the building sector has the largest share of energy consumption in most countries of the world, this paper focused on the study of one of the most important of the buildings which are the airports. Airports can play a major role in reducing the burden on the electrical grid as they have several factors that make them optimum models for applying energy efficiency strategies. Accordingly, the contribution in this paper is achieved by applying a Fuzzy Logic Control (FLC) scheme to improve the energy efficiency of the Egyptian airports without compromising the comfort level of the occupants and validating the obtained results by the aid of "DesignBuilder" software conducted with the "EnergyPlus" simulator, which is a state-of-the-art 3D simulator tool for checking building energy, carbon, lighting, and comfort performance. The applied 3D simulator evaluates the impacts of implementing the proposed fuzzy control system instead of ON/OFF control schemes or Building Management System (BMS). In this context, case studies were conducted at three different Egyptian airports as a high, medium, and low occupancy level airports respectively to discuss the opportunities and challenges of applying the fuzzy logic scheme in airports according to the occupancy level.
\end{abstract}

Copyright $@ 2020$ Institute of Advanced Engineering and Science. All rights reserved.

\section{Corresponding Author:}

Mohamed Abdul Raouf Shafei,

Electrical Power Engineering Department,

Faculty of Engineering, Cairo University,

1 Gamaa Street, Giza, Egypt.

Email: mohamed.shafei@eng.cu.edu.eg

\section{INTRODUCTION}

The building sector has been a major focus of research in recent decades as it is considered the largest consumer of energy. There are a lot of studies which all aim to reduce the energy consumption in the building sector. Typically, airports are one of the most buildings consuming energy due to their large energy demand needed to supply main loads of both land-side and air-side. However, airports have many distinguished factors such as the large consumption, geographical site, security, availability of large spaces and the nature of nonlinear loads; these factors make the airports act as optimum models for implementing energy efficiency strategies. Therefore, the airports can contribute in facing energy and environment challenges.

Several studies of energy efficiency in airports have included: the use of building management system (BMS) to control airports heating, ventilation, and air conditioning (HVAC) loads through a lot of sensors as presented in [1], using FLC system to control the load of the airport according to the occupancy is introduced in [2]. In another side, other researchers have focused on enhancing the architecture design to provide the building with a good insulation level thus reducing the energy consumed by HVAC [3], or increasing temperature setpoints, air handling unit (AHU) rescheduling and window films replacement [4]. Also, studying the effects of the air ventilation in building and its impacts on the HVAC loads is introduced in [5], in addition to increasing the glass performance or using double glass to reduce HVAC consumption [6]. 
This paper will focus on applying FLC systems for demand managing in airports without disturbing the level of passenger comfort with the aid of 3D simulator tool for modeling and simulation of the airport building. Accordingly, three case studies at Sharm-Elshiekh, Luxor and Taba airports were carried out to compare the usage of conventional control system versus fuzzy control systems and determine the savings achieved by controlling airport loads according to occupancy and its impacts on the comfort of occupants.

\section{AIRPORTS AND COMFORT LEVEL}

The main goal of airports is to provide the passengers with the required services in a comfort way $[7,8]$. Generally, the loads at airports are typically divided into: critical loads such as airfield lighting, security devices, checking areas and all navigation aids and non-critical loads such as passenger's terminal building, chiller station building [9]. In fact, the terminal building has the majority of the airport consumption; thus, the proposed energy efficiency strategy will be implemented in the terminal building taken into account not negatively affecting the comfort level of occupants, and excluding all the critical loads such as security and any of navigation loads.

The main parameters of comfort are thermal comfort, visual comfort and indoor air quality, in addition to some other factors that affect the comfort of occupants in general such as indoor pollutants' concentration, building services, personal factors and preferences, building's physical conditions, and external weather conditions [10]. This paper will focus on the thermal comfort and its indices as it is directly related to the HVAC loads (heating, ventilation, and air conditioning), which have the major consumption of the airport energy. According to [11], the thermal comfort is the result of the interaction between environmental factors and individual factors based on Fanger's PMV equation.

"Fanger's comfort equation" is the combined quantitative combination of the environmental and individual variables. PMV (Predicted Mean Vote), as the result of "Fanger's comfort equation", indicates how the occupants judge the climate. Using PMV, the Percentage of People Dissatisfied (PPD) can be predicted. PMV-PPD (Predicted Percentage of Dissatisfied occupants) indices are widely accepted criteria for thermal comfort evaluation based on Fanger's model [12]. According to the international standards [13], a PMV index ranging between \pm 0.5 offers high levels of thermal comfort and thus the highest level of user acceptability. Table 1 illustrates the levels of PMV values, which are used to express the degree of people satisfaction of thermal condition.

Table 1. TASHRAE thermal sensation scale of PMV

\begin{tabular}{cccc}
\hline Sensation & PMV & Sensation & PMV \\
\hline Hot & +3 & Slightly Cool & -1 \\
Warm & +2 & Cool & -2 \\
Slightly Warm & +1 & Cold & -3 \\
\hline
\end{tabular}

The PMV equation is the quantitative combination of activity, clothing, air temperature, mean radiant temperature, air velocity and relative air humidity. Fanger's PMV correlation is based on the identification of a skin temperature $T_{s k, r e q}$ and sweating rate $q_{\text {sweat,req }}$ required for "optimal" comfort conditions, using the data from [12], and as expressed by the following (1), (2):

$$
\begin{aligned}
& T_{\text {sk,req }}=96.3-0.156 q_{\text {met, heat }} \\
& q_{\text {sweat }, \text { req }}=0.42\left(q_{\text {met, heat }}-18.43\right)
\end{aligned}
$$

Where the metabolic heat loss $q_{m e t, h e a t}$ is the difference between the metabolic generation $M$ and that converted to work $\omega$. (e.g., lifting, running) as follows (3):

$$
q_{m e t, h e a t}=M-\omega
$$

Where $T_{s k, r e q}$ denotes the average skin temperature in ${ }^{\circ} \mathrm{F}, M$ presents the rate of metabolic generation per unit DuBois surface area in Btu/h $\mathrm{ft}^{2}$ and $\omega$. is the human work per unit DuBois surface area in Btu/h $\mathrm{ft}^{2}$.

With reference to [12], PMV is correlated as a function of the thermal load, $L$, on the body, defined as the difference between the rate of metabolic heat generation and the calculated heat loss from the body to the actual environmental conditions assuming these optimal comfort conditions. The convection and radiation heat transfer are functions of clothing temperature, which is affected by skin temperature. The evaporative losses are directly influenced by skin temperature. 
$L=q_{m e t, \text { heat }}-f_{c l} h_{c}\left(T_{c l}-T_{a}\right)-f_{c l} h_{r}\left(T_{c l}-T_{r}\right)-156\left(W_{s k, r e q}-W_{a}\right)-0.42\left(q_{m e t, h e a t}-\right.$

$18.43)-0.00077 M\left(93.2-T_{a}\right)-2.78\left(0.0365-W_{a}\right)$

Where:

$T_{c l}=$ average surface temperature of clothed body, ${ }^{\circ} \mathrm{F}$,

$f_{c l}=$ ratio of clothed surface area to DuBois surface area (Acl/AD),

$R_{c l}=$ effective thermal resistance (R-value) of clothing, $\mathrm{ft}^{2 \circ} \mathrm{F} \mathrm{h} / \mathrm{Btu}$,

$T_{a}=$ air temperature, ${ }^{\circ} \mathrm{F}$,

$h_{c}=$ convection heat transfer coefficient, Btu/h $\mathrm{ft}^{2}{ }^{\circ} \mathrm{F}$,

$T_{r}=$ mean radiant temperature, ${ }^{\circ} \mathrm{F}$ or ${ }^{\circ} \mathrm{R}$,

$h_{r}=$ radiative heat transfer coefficient, $\mathrm{Btu} / \mathrm{h} \mathrm{ft}^{2}{ }^{\circ} \mathrm{F}$,

$W_{a}=$ air humidity ratio,

$W_{s k, r e q}=$ saturated humidity ratio evaluated at the skin temperature.

Finally, the following correlation between PMV and the thermal load is briefed as follows:

$P M V=3.155\left(0.303 e^{-0.114 M}+0.028\right) L$

According to [2], the PPD illustrates whether an environment is acceptable or not, while the PMV explains that the discomfort percentage of $25 \%$ is also approved and can be translated to PMV of \pm 1 . Figure 1 shows that usually about 5\% of the total percentage will be out of the comfort limits [13]. An indoor thermal environment that has a PPD of less than $10 \%$ corresponding to a PMV of about \pm 0.5 is considered acceptable [14]. Recently, ASHRAE Standard 55 has shown that the acceptable percentage may reach $80 \%$ (PMV of \pm 0.73 ) or more $[15,16]$. The PPD also can be determined by the following $(6)$ :

$$
\mathrm{PPD}=100-95 \times \mathrm{e}^{-\left(0.03353 \times \mathrm{PMV}^{4}+0.2179 \times \mathrm{PMV}^{2}\right)}
$$

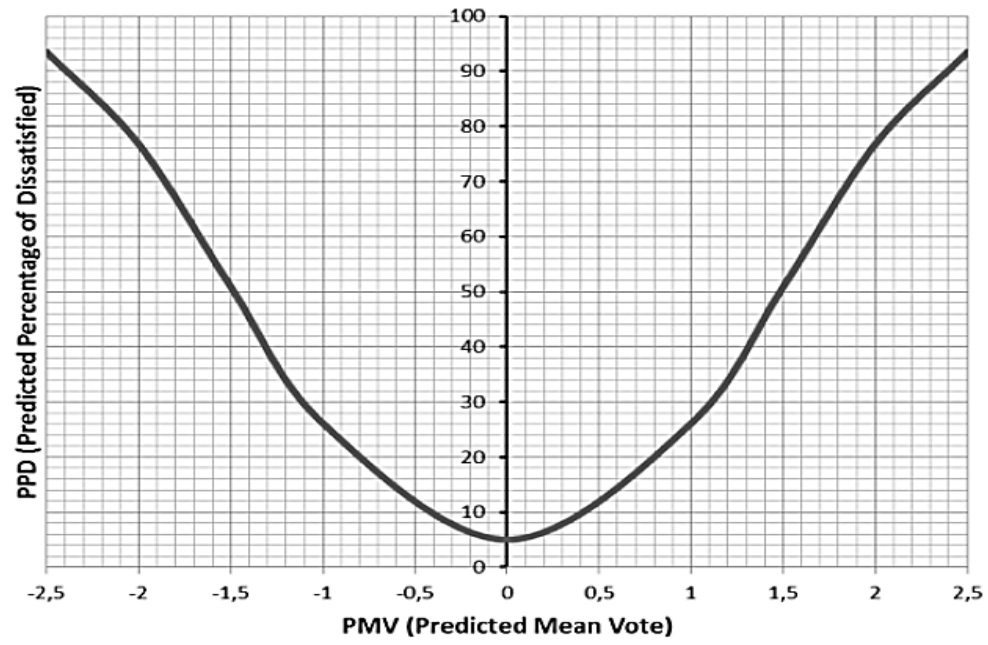

Figure 1. Relationship between PMV and PPD [13]

\section{DESIGN ANALYSIS AND METHODOLOGY}

Generally, control technologies can be classified into conventional and intelligent controllers [17]:

a) Conventional controllers namely: ON/OFF and proportional integral derivative (PID) controllers attempt to translate one or more strictly defined input variables into one or more precisely defined control signals using the mechanisms of numerically defined control process or algorithms [18]. Nonetheless, HVAC system's operating environment is a complex non-linear environment, as it depends on more loosely defined variables, such as the thermal comfort, than those usually expected to be interpreted by a conventional controller.

b) Smart control systems :such as fuzzy systems have all the features that make them qualified to solve the problems that have emerged in conventional control systems, and thus reducing energy consumption while maintaining passenger comfort [19].

Fuzzy control scheme for energy efficiency and demand management in ... (Mohamed Abdul Raouf Shafei) 
According to [20], using conventional controllers as building management system (BMS), whose functions are based on ON/OFF, temperature control and in some cases humidity control are not the ultimate solutions to save energy. The reason behind the above fact is that, conventional controllers do not take into account real time events such as the number of occupants; indoor air quality (IAQ), natural light illuminations and etc. dislike fuzzy logic based controllers. Recently, there is a high attention to study fuzzy logic based controllers as they are able to save energy while maintaining indoor comfort level.

\subsection{Fuzzy logic controller (FLC)}

Based on the above, it is necessary to provide the airport with a control system that can rationalize the energy consumption with maintaining the level of comfort. Consequently, the smart control systems such as fuzzy and artificial neural networks (ANN), have been appeared which can replace the operator by providing an algorithm that can identify the optimum setpoints and apply them at the appropriate time.

Fuzzy logic controller is the algorithm which takes the external conditions of temperature, lighting and number of occupants as inputs and analyzes this data according to the functions and equations prepared in advance. It extracts the data for optimum operation of the airport in an analog image from 0:1 to reduce energy consumption without disturbing the level of passenger comfort. The fuzzy controller has the ability to handle the nonlinear loads as found at the airports, in addition to it can differentiate between building states if they are occupied or not. Therefore, the loads can be operated optimally according to the proper setpoints which provide less energy consumption while maintaining the comfort of occupants.

The FLC scheme provides a convenient way to map an input space to an output space. Specifically, a fuzzy inference system interprets the values in the input vector and, based on some set of rules, assigns values to the output vector. The mapping then provides a basis from which decisions are made, or patterns discerned [21]. The FLC passes through four processes to extract the outputs, these processes are: fuzzification, inference engine, rule base and defuzzification, this processes: interacting as illustrated in Figure 2 [2].

\subsection{Applied Software tools for dynamic energy modeling}

Typically, "DesignBuilder" software acts as a framework [22] to draw and build up the model of the airport building and conducted to "EnergyPlus" simulator [23] to analyze the outputs of the simulation (Figure 3 illustrates the relationship between them). Fuzzy toolbox in MATLAB receives the input data of occupancy, weather conditions, and external lighting, then analyzes and processes them to extract the outputs, which are the setpoints of the system. These set points will be converted to compact schedules, then inserted as inputs to "DesignBuilder" to evaluate the schedules of the temperature, lighting, and ventilation with respect to the selected code ASHRAE or CISBE.

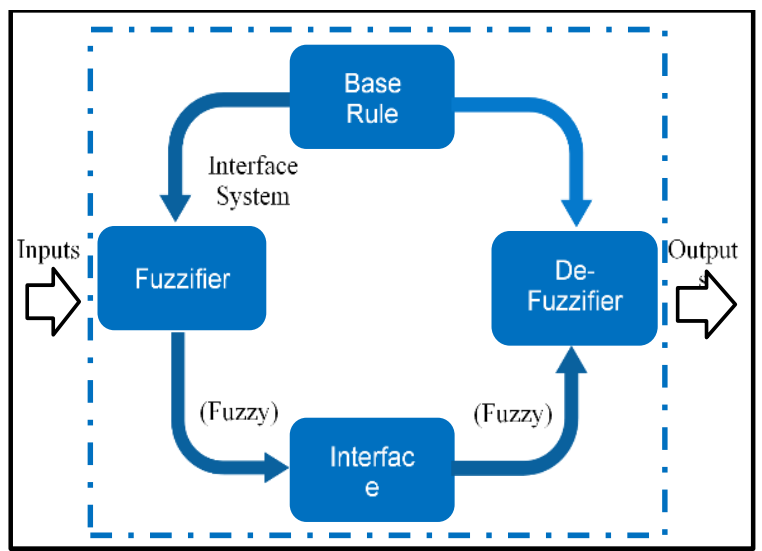

Figure 2. Configuration of the Fuzzy system

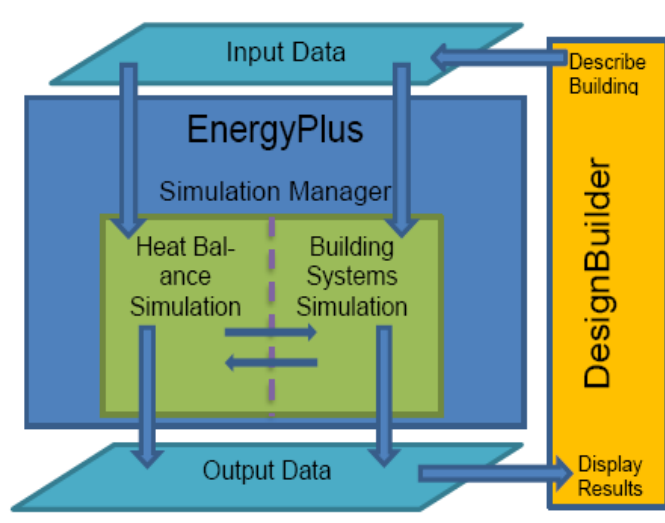

Figure 3. Relationship between "EnergyPlus" and "DesignBuilder"

\subsection{Calculating saving using fuzzy control}

To determine the amount of energy savings of controlled building, the building energy load should be determined and compared using conventional PID controllers and then using fuzzy based controllers. In fact, building parameters are governed by two thermal balance as shown in (7) is due to total heat gain and (8) represents the sensible heat gain [24]: 


$$
\begin{aligned}
& \frac{d T}{d t}=\frac{U A}{c a p}\left(T_{\text {amp }}-T_{\text {set }}\right)+\frac{m_{\text {vent }}}{c a p}\left(T_{\text {vent }}-T_{\text {set }}\right)+\frac{m_{\text {inf }} c p_{\text {air }}}{c a p}\left(T_{\text {inf }}-T_{\text {set }}\right)+\sum Q_{\text {gain }} \\
& \sum Q_{\text {gain }}=Q_{\text {lights }}+Q_{\text {equip }}+Q_{\text {people }}+Q_{\text {infl }}+Q_{\text {vents }}+Q_{\text {solar }}
\end{aligned}
$$

Where $T$ is zone temperate $\left({ }^{\circ} \mathrm{C}, U\right.$ is the building loss coefficient $\left(\mathrm{kW} / \mathrm{hr} . \mathrm{m}^{2} \cdot{ }^{\circ} \mathrm{C}\right), A$ is the space over all area $\left(\mathrm{m}^{2}\right)$, capis the building capacitance $\left(\mathrm{kW} /{ }^{\circ} \mathrm{C}\right), T_{\text {set }}$ is the space set temperature $\left({ }^{\circ} \mathrm{C}\right), m_{\text {vent }}$ is the ventilation air mass flow rate $(\mathrm{kg} / \mathrm{hr}), C p_{\text {air }}$ is the specific heat of building air $\left(\mathrm{kW} / \mathrm{kg} .{ }^{\circ} \mathrm{C}\right), T_{\text {vent }}$ is the temperature of ventilation $\operatorname{air}\left({ }^{\circ} \mathrm{C}\right), m_{\text {inf }}$ is the mass flow rate of infiltration air $(\mathrm{kg} / \mathrm{hr}), T_{\text {inf }}$ is the temperature of infiltration air $\left(\mathrm{C}^{\circ}\right), Q_{\text {gain }}$ isthe sensible heat gain $(\mathrm{kW}), Q_{\text {lights }}$ is the heat gain resulting from lights, $Q_{\text {equip }}$ is the heat gain resulted from equipment used in the building including computers and printers $(\mathrm{kW}), Q_{\text {people }}$ is the sensible heat gain resulted from people $(\mathrm{kW}), Q_{\text {infl }}$ is the sensible heat gain from infiltration (kW), $Q_{\text {vents }}$ is the sensible heat gain due to ventilation and finally $Q_{\text {solar }}$ is the heat gain due to sun radiation $(\mathrm{kW})$. As shown in (9) governs the building heat balance due to sensible heat gain, while the total building sensible heat gain is calculated using (10).

$$
\begin{aligned}
& \frac{d w}{d t}=\frac{m_{\text {inf }}}{\rho V}\left(w_{\text {vent }}-w\right)+\frac{\sum w_{\text {gain }}}{\rho V} \\
& \sum w_{\text {gain }}=w_{\text {people }}+w_{\text {infl }}+w_{\text {vents }}+w_{\text {equips }}
\end{aligned}
$$

Where $w$ is the heat gain due to air moisture content $(\mathrm{kW}), \rho$ is the density of building air $\left(\mathrm{kg} / \mathrm{m}^{3}\right), V$ is the building volume $\left(\mathrm{m}^{3}\right), w_{\text {gain }}$ is the total heat gain due to moisture content of the air (latent), $w_{\text {people }}$ is the latent heat gain from people $(\mathrm{kW}), w_{\text {infl }}$ is the latent heat gain from infiltration $(\mathrm{kW}), w_{\text {vent }}$ is the latent heat gain due to ventilation $(\mathrm{kW})$, and $w_{\text {equips }}$ is the latent heat gain using equipment and cooking $(\mathrm{kW})$. Consequently, the potential of energy saving $E_{\text {saved }}$ can be evaluated based on a comparison between a conventional controller system and a FLC based system which is expressed by (11):

$$
E_{\text {saved }}=E_{\text {conv }}-E_{\text {fuzzy }}
$$

Where $E_{\text {conv }}$ is the conventional system electric power $(\mathrm{kW})$ and $E_{f u z z y}$ is the FLC based system electric power $(\mathrm{kW})$. In addition, the controlled building consumed energy using conventional PID Controllers can be estimated using (12):

$$
E_{\text {conv }}=w_{\text {gain }}+E_{\text {light }}+E_{\text {equip }}
$$

Where $E_{\text {light }}$ is the needed energy for lighting system and $E_{\text {equip }}$ is energy needed to power other equipment operated in the building using conventional control system. The building consumes energy using FLC is calculated as expressed in (13):

$$
E_{\text {fuzzy }}=w_{\text {gain }}+E_{\text {light }}+E_{\text {equip }}
$$

The previous equations are derived for the mathematical calculations of the saving that can be achieved through applying FLC instead of the BMS control system.

\section{CASE STUDIES OF DIFFERENT OCCUPANCY' AIRPORTS}

Case studies were conducted at Sharm-Elshiekh, Luxur, and Taba airports. Strategy simulations were carried out using the "DesignBuilder" program, which is conducted with the "EnergyPlus" program; to compare the usage of conventional control system versus FLC systems and determine the savings achieved by controlling airport loads according to occupancy.

\subsection{Sharm-elshiekh airport}

Sharm-Elsheikh international airport locates in South Sinai, Egypt with the longitude and latitude of $27^{\circ} 58^{\prime} 38^{\prime \prime} \mathrm{N} 34^{\circ} 23^{\prime} 41^{\prime \prime} \mathrm{E}$, in 18 kilometers (11 miles) northeast from the city of Sharm-Elshiekh. It possesses two passenger terminals: Terminal-2 (the old one) and Terminal-1 (the new one). Actually, the consumption of Sharm-Elsheikh airport's terminal building can be classified into four main categories of loads: HVAC, lighting, hot water, motors and miscellaneous. For energy consumption in Terminal-1, 
HVAC consumes $70.5 \%$, the lighting consumes $6.5 \%$, the hot water consumes $1.4 \%$ while the other miscellaneous consume $21.6 \%$. Therefore, the proposed strategy can be applied for Terminal-1 achieving energy efficiency opportunities through two dimensions as will be described in next section. 3D Modeling of Sharm-Elsheikh as shown in Figure 4.

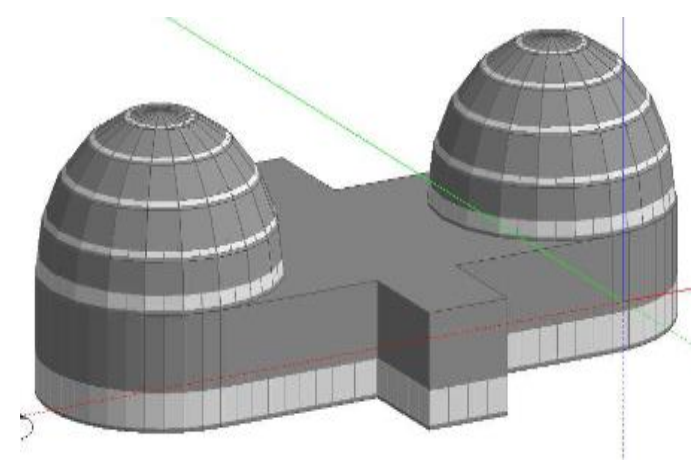

Figure 4. 3D Modeling of Sharm-Elsheikh terminal-1 building

As the existing applied control system in Sharm-Elsheikh airport is Building Management System (BMS), a model for simulating the airport will be presented to compare between BMS system with the proposed FLC system. shows the 3D model of Terminal-1 in the airport at "DesignBuilder" tool.

a) The case of BMS control system: HVAC and lighting systems were scheduled according to the predefined schedules by the designer. The temperature setpoints of between $21{ }^{\circ} \mathrm{C}$ and $23{ }^{\circ} \mathrm{C}$ were applied to all the indoor spaces of the terminal building to simulate the energy and thermal comfort in this case.

b) For the energy saving scenario (Fuzzy model): compact schedules are created from the outputs of FLC which represent temperature, lighting and airflow rates setpoints. These schedules are applied to the terminal building spaces except some indoor spaces (offices, shops, security and any of the critical loads).

The comparison between the two systems (existing BMS, proposed FLC) for Terminal-1 can be presented as follows:

\subsubsection{Energy consumption}

The results, shown in Figures 5 and 6, ensured that the FLC has succeeded in reducing energy required for lighting and HVAC loads over the year by up to 50-59\% and 15 to $37 \%$ respectively. These savings were achieved by controlling the operating schedules of lighting and HVAC according to real occupancy and weather conditions. Consequently, as the HVAC and the lighting loads are the most energy consuming loads, the reduction in their energy consumptions has directly resulted in reducing the total energy consumption over the year. It can be concluded that the FLC system has contributed to saving energy consumption by 13.5 to $25 \%$ over the year as deduced from Figure 7 .

\subsubsection{Produced emissions}

The proportion of carbon emissions generated from the building is commensurate with the amount of energy consumed. Therefore, the reduction in energy consumption by FLC has directed in the reduction of carbon emissions by $12.5-25 \%$ over the year according to the rationalization of energy. Thus, it can be concluded that the FLC system has provided the required energy as well as contributing in improvement of the environmental climate.

\subsubsection{PMV index}

The basic principle of using the FLC is to improve energy usage to consume the least possible energy while maintaining the acceptable level of comfort of \pm 0.5 . As shown in Figure 8, it can be concluded that FLC has succeeded in rationalizing energy consumption without compromising the level of comfort of occupants. In fact, the FLC system has already improved the PMV value from -0.46 and 0.45 to -0.12 and 0.5 for all the months over the year except August and October, as the recorded PMV was $0.6 \& 0.8$ respectively. However, these values are still acceptable as they are within the range of \pm 1 which is accepted for large spaces as discussed in [25]. 


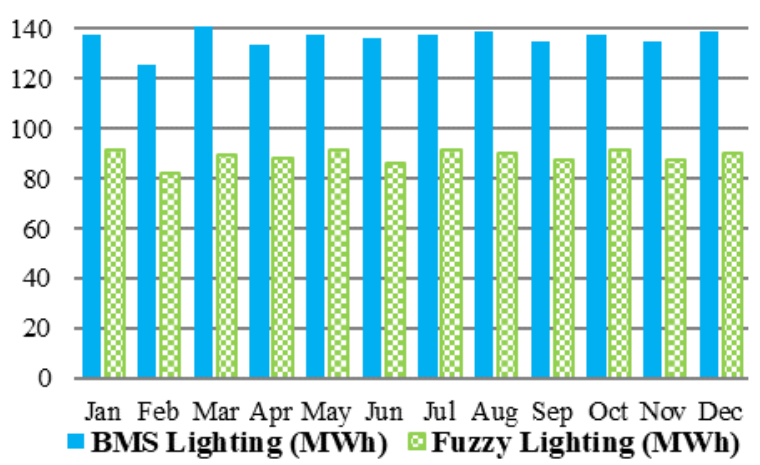

Figure 5. Comparing BMS \& FLC in saving lighting consumption for Terminal-1 of Sharm-Elsheikh airport

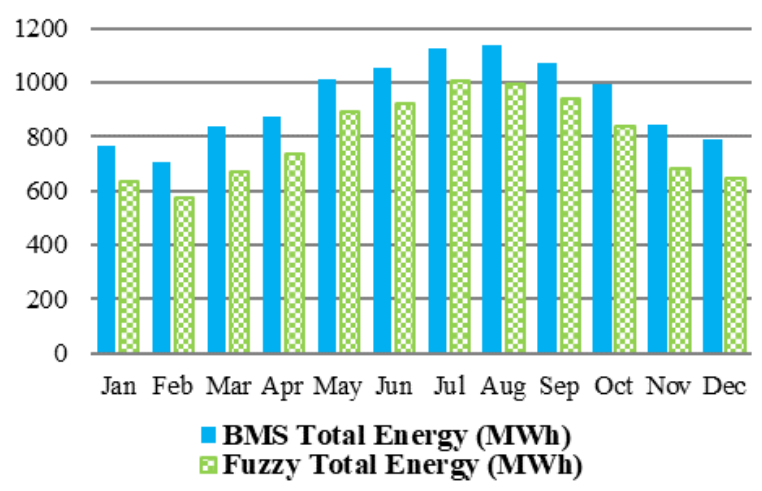

Figure 7. Comparing BMS \& FLC in saving total energy consumption for Terminal-1 of SharmElsheikh airport

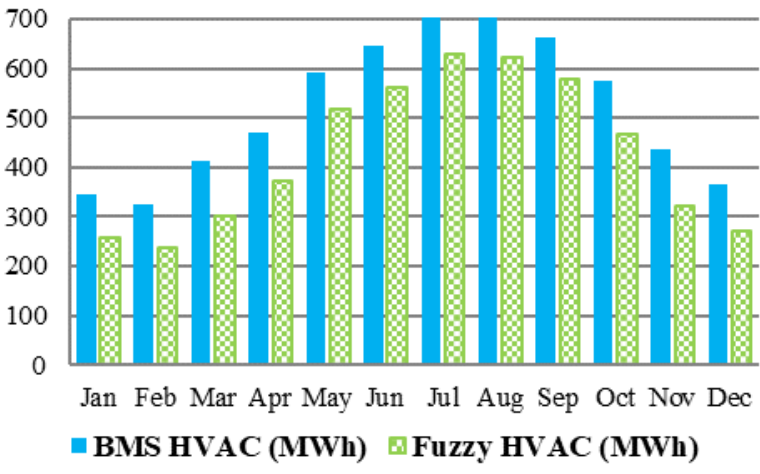

Figure 6. Comparing BMS \& FLC in saving HVAC consumption for Terminal-1 of Sharm-Elsheikh airport

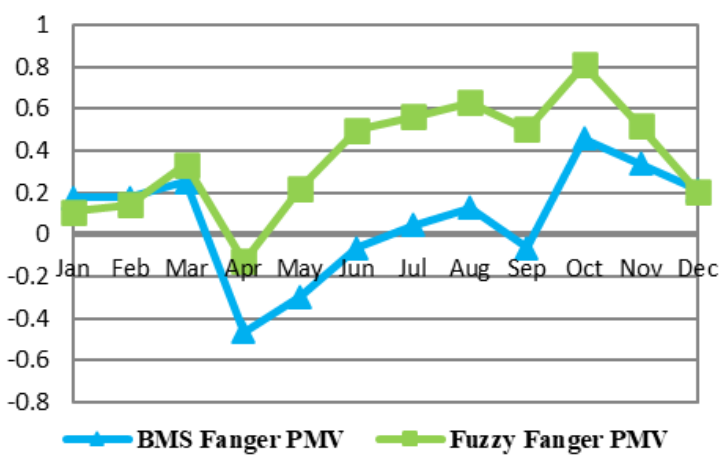

Figure 8. PMV comparison between BMS \& FLC for Terminal-1 of Sharm-Elshiekh airport

\subsection{Luxur airport}

Luxor international airport is presented here as a model for medium occupancy airports in Egypt. It is located at Luxor city in Egypt with a coordinates of $25^{\circ} 40^{\prime} 15^{\prime \prime} \mathrm{N}, 32^{\circ} 42^{\prime} 23^{\prime \prime}$ E. It is the main airport serving the city; it is $6 \mathrm{~km}$ from the east of the city. Many charter airlines use this airport, as it is a popular tourist's destination. Figure 9 shows the 3D model of Terminal building in the airport.

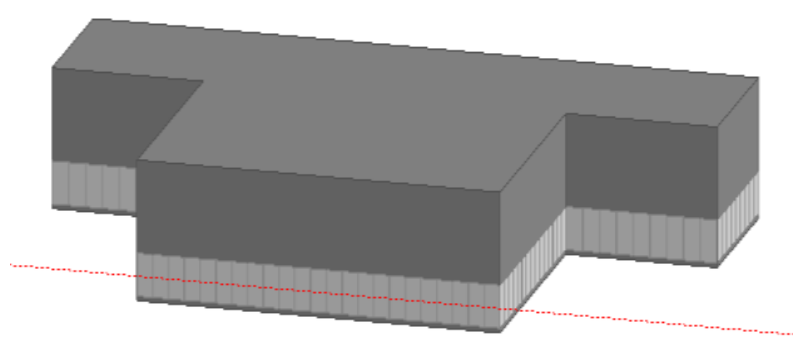

Figure 9. 3D Modeling of Luxor terminal building

The HVAC consumes the largest amount of energy which represents $60 \%$ of the total consumption, the lighting load also consumes about $10 \%$ of the terminal consumption and finally the last $30 \%$ is distributed between remaining loads. BMS control system is applied in Luxor airport to manage the loads of HVAC, lighting and others. The BMS system controls the loads of the airport through a network of sensors. 
a) Using FLC instead of the BMS controller, results in average 55\% saving in lighting loads as shown in Figure 10. In fact, day lighting control is also included as the lights are dimed or switched-off depending on the adequacy of the daylight luminance within the building.

b) Average saving is rounding of $26.2 \%$ in HVAC consumption resulted from using FLC with the optimum setpoints as shown in Figure 11. Actually, the consumption for both systems (BMS and FLC) don not consume large energy for the heating loads at the winter because of the fine weather, so the major loads of HVAC system were cooling in summer season and ventilation to provide the fresh air according to the need.

c) As a result of saving in lighting loads and HVAC loads, using FLC system with the optimum setpoints could save about $17 \%$ of the annual consumption of the airport over the BMS control system as shown in Figure 12. Consequently, about $14.9 \%$ of the total annual produced emissions can be avoided by using the FLC system at the airport.

d) Also, the FLC system keeps the PMV values in the accepted range as shown in Figure 13.

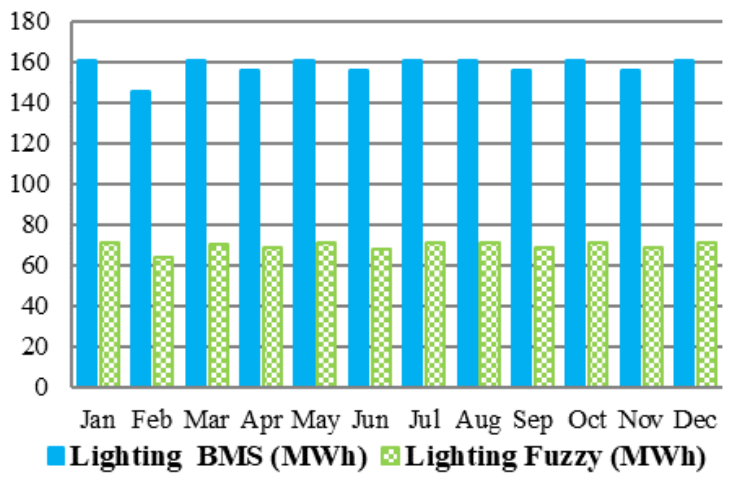

Figure 10. Comparing BMS and FLC in saving lighting consumption for Luxor airport

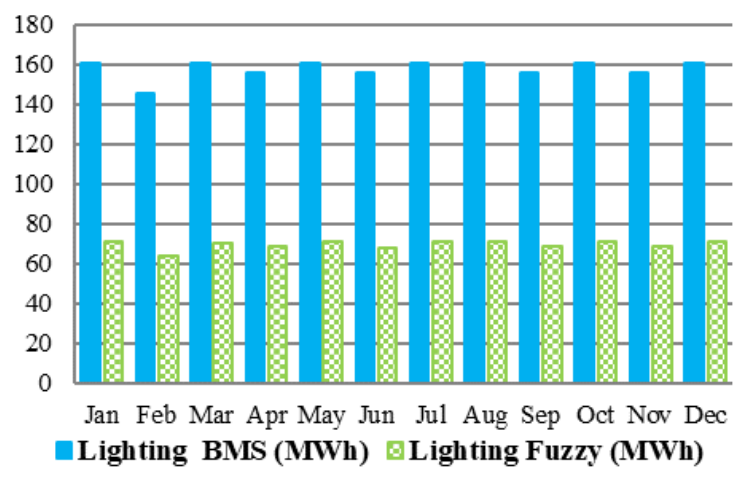

Figure 12. Comparing BMS and FLC in saving total energy for Luxor airport

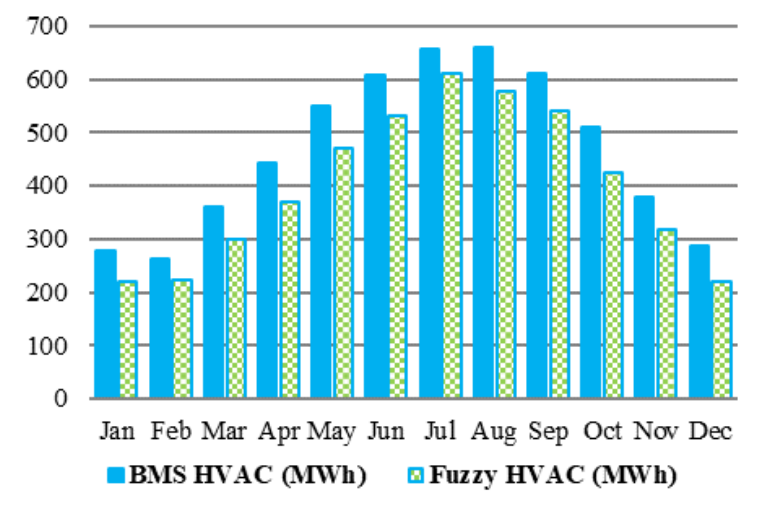

Figure 11. Comparing BMS and FLC in saving HVAC consumption for Luxor airport

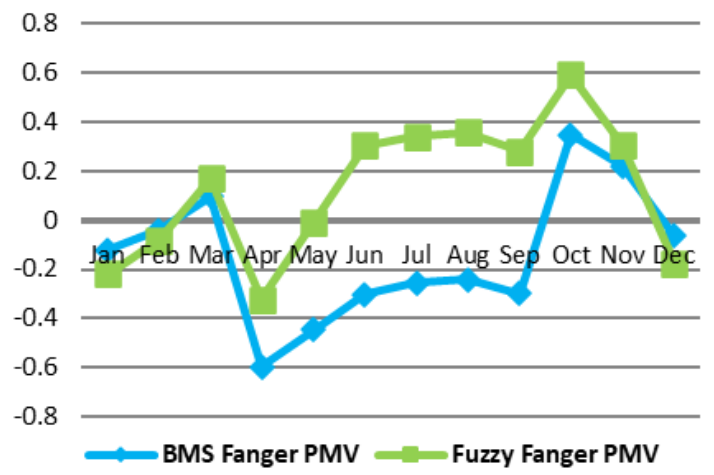

Figure 13. PMV comparison between BMS \& FLC for Luxor airport

\subsection{Taba airport}

The third level of occupancy is low; therefore Taba airport is presented as a model of low occupancy airport in Egypt. It is an international airport located in Sinai, with coordinates of $29^{\circ} 35^{\prime} 16^{\prime \prime} \mathrm{N}$, $34^{\circ} 46^{\prime} 41^{\prime \prime}$ E. The major load at the terminal building is the HVAC, which shares with about $65 \%$ of the total consumption, the lighting loads come in second rank with $13 \%$, and about $22 \%$ of the total consumption goes to the other loads such as motors, elevators and pumps. As the airport is not occupied and located in Sinai, which has many airports, the airport, still uses the conventional control ON/OFF control system. Thus, the staff of the airport, as needed, operate the loads. Figure 14 shows the 3D model of Terminal building in the airport. 


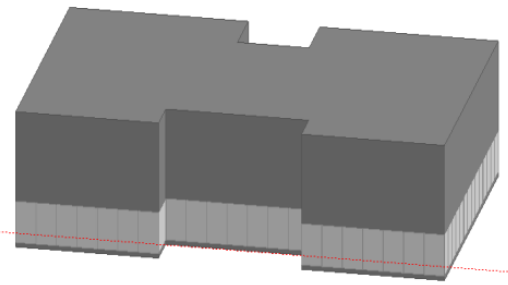

Figure 14. 3D Modeling of Taba airport

As a matter of fact, this airport does not consume a large amount of energy for lighting as the occupancy is low; besides the lighting consumption does not have great differences all over the year. However, using FLC instead of the conventional controller results in an average about $48 \%$ saving in lighting loads.

a) Actually, HVAC consumption is larger at the summer season to face the high temperature as shown in Figure 15, where it is low in winter because the low need for heating. An average of $26.5 \%$ saving in HVAC consumption is achieved by using FLC with the optimum setpoints.

b) In general, the total energy consumption is lower than what recorded in Sharm-Elsehiekh and Luxor airports because of the low occupancy at the airport which is reflected on the operation of the loads. Moreover and as expected, the airport consumes more energy at summer season for HVAC loads. According to Figure 16, FLC provides an opportunity to save about $13.5 \%$ of the annual consumption of the airport over the conventional ON/OFF control system.

c) As a result of the energy saving, it is illustrated in Figure 17 that using FLC will save about $13 \%$ of the total annual produced emissions from the airport.

Although, FLC has improved the PMV values of the building, but some of the results still out of the comfortable limits. According to the results of Figure 18, such uncomfortable values occur at the summer months, when the HVAC does not operate for a long time because of the low occupancy of the airport. This issue is in contrast to the Sharm-Elshiekh airport which has a high occupancy results in an acceptable values of PMV.

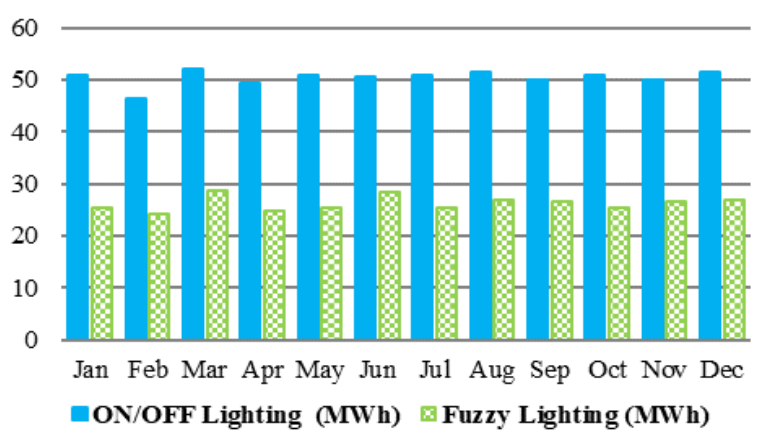

Figure 15. Comparing ON/OFF controller and FLC in saving lighting consumption for Taba airport

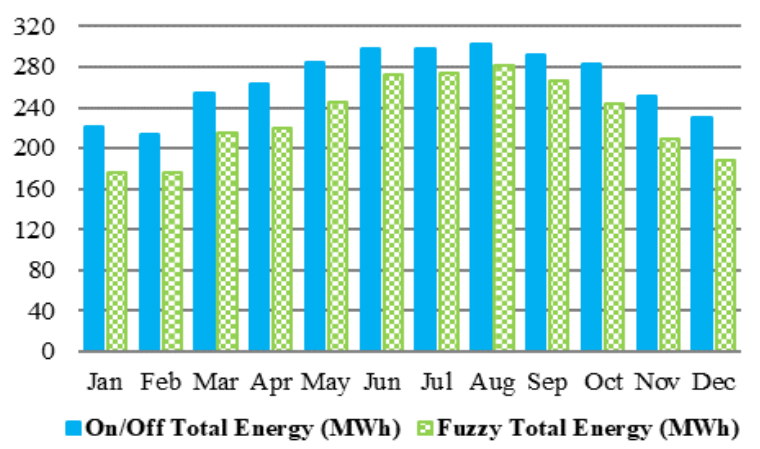

Figure 17. Comparing ON/OFF controller and FLC in saving total energy consumption for Taba airport

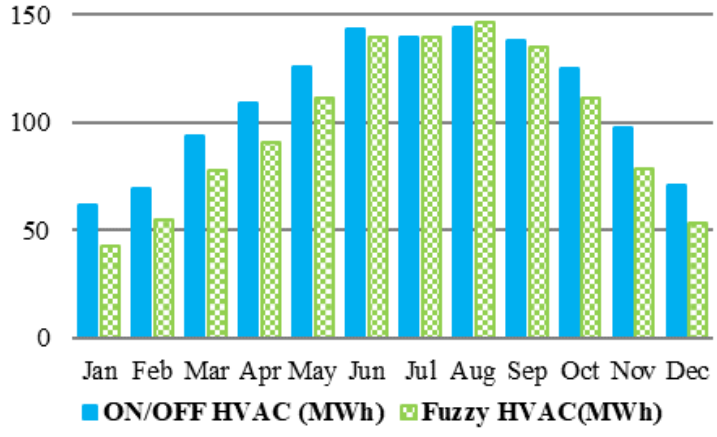

Figure 16. Comparing ON/OFF controller and FLC in saving HVAC consumption for Taba airport

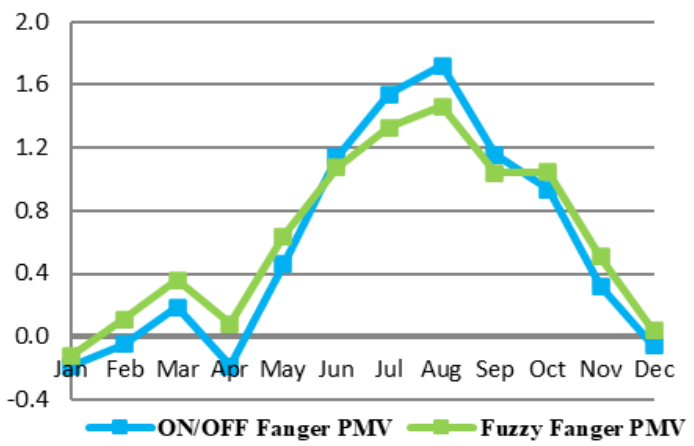

Figure 18. PMV comparison between ON/OFF controller \& FLC for Taba airport 


\section{CONCLUSION}

This study has investigated the airports buildings for improving the energy efficiency in Egypt as they can contribute in reducing the burden on the electrical grid which directly reflects on the environmental side. The results showed that the proposed strategy has significantly improved the utilization of energy in three different airports with different occupancy rate. The proposed FLC system is applied to control the loads of the Terminal-1 instead of the currently BMS system in Sharm-Elshiekh \& Luxur airports and the ON/OFF system in Taba airport.

In fact, the simulations of the tested control systems are performed in the same conditions and using the same parameters for the three studied airports, almost all systems have provided occupants comfort. However, the FLC system was able to offer the occupants comfort level with lower energy consumption. It has resulted in that the rationalization of the total energy consumption is varied according to the occupancy level. The obtained results are showing that the total annual saving in energy for the three airports are rounding from $13.5 \%$ to $20 \%$, which is positively reflected on the environmental side as the carbon emissions have declined by about the same percentage. It should be noted that this reduction in energy consumption is achieved without decreasing the level of comfort for passengers. On the contrary, the results have ensured that the level of comfort is always within acceptable limits and also has been improved in some periods than the recorded for the BMS or ON/OFF systems.

\section{REFERENCES}

[1] L. Pereira, et al, "Improving energy efficiency and cost reduction in airports contributions from a wireless network web-based monitoring solution," Energy Procedia, vol. 78, pp. 2178-2193, 2015.

[2] A. Mambo, Occupancy driven supervisory control of indoor environment systems to minimise energy consumption of airport terminal building, 2013.

[3] M. Uysal and M. Sogut, "An integrated research for architecture-based energy management in sustainable airports," Energy, vol. 140 Part 2, pp. 1387-1397, 2017.

[4] L. Perdamaian, R. Budiartoa and M. Kholid, "Scenarios to reduce electricity consumption and CO2 emission at Terminal 3 Soekarno-Hatta International Airport," Procedia Environmental Sciences, vol. 17, pp. 576-585, 2013.

[5] L. Zhao, Q. Meng and Q. Li, "Energy efficiency design of an airport terminal building," in International Conference on Advances in Energy Engineering, pp. 251-255, 2010.

[6] J. Zhua and D. Li, "Current situation of energy consumption and energy saving analysis of large public building," Procedia Engineering, vol. 121, pp. 1208-1214, 2015.

[7] S. Kumar and W. J. Fisk, "IEQ and the impact on building occupants," ASHRAE Journal, vol. 44, no. 4, pp. 50:53, 2002.

[8] H. A. S. Executive, Thermal Comfort in The Workplace: Guidance for Employers, UK, 1999.

[9] A. Abdelrazik, M. Hamad and A. Helal, "Energy Saving Feasibility Study using a Concentrating Solar Power Plant for Borg El-Arab International Airport, Egypt," in International Conference on New Trends for Sustainable Energy (ICNTSE), 2016.

[10] A B Shepherd and W J Batty, "Fuzzy control strategies to provide cost and energy efficient high quality indoor environments in buildings with high occupant densities," Building Service Engineering Research and Technology, vol. 4, no. 1, pp. 35-45, 2003.

[11] C. Ekici, "A Review of Thermal Comfort And Method of Using Fanger's PMV Equation," in 5th International Symposium on Measurement, Analysis and Modelling of Human Functions, 2013.

[12] R. Ruppa, N. Vásquez and R. Lamberts, "A review of human thermal comfort in the built environment," Energy and Buildings, vol. 105, pp. 178-2015, 2015.

[13] I. S. 7730, Ergonomics of the Thermal environment: analytical determination and interpretation of thermal comfort using calculation of the PMV and PPD indices and local thermal comfort criteria, 3rd ed., 2005.

[14] D. Oughton and S. Hodkinson, Faber \& Kell's heating and air conditioning, 2008.

[15] B. Olesen and G. Brager, A better way to predict comfort: The new ASHRAE standard 55-2004, UC Berkeley: Center for the Built Environment, 2004.

[16] ASHRAE Standard 55-2004, Thermal Condition for Human Occupancy, 2004.

[17] A. a. C. C. Dounis, "Advanced control systems engineering for energy and comfort management in a building environment," Renewable and Sustainable Energy Reviews, vol. 13, no. 6-7, pp. 1246-1261, 2009.

[18] A. C. G. R. D. Subbaram Naidu, "Advanced control strategies for HVAC\&R systems-An overview: Part II: Soft and fusion control," HVAC \& R Research, vol. 17, no. 2, pp. 144-158, 2011.

[19] S. L. D. C. P. U. M. M Gouda, "Thermal comfort based fuzzy logic controller," Building Services Engineering Research and Technology, vol. 22, no. 4, pp. 237-253, 2001.

[20] M. R. M. K. Yazeed Yasin Ghadi, "Potential of saving energy using advanced fuzzy logic controllers in smart buildings in subtropical climates in Australia," Energy Procedia, vol. 61, pp. 290-293, 2014.

[21] E. Mamdani, "Application of fuzzy logic algorithm for control of simple dynamic plant," Proceedings of the Institution of Electrical Engineers, vol. 121, no. 12, pp. 1585-1588, 1974.

[22] [Online]. Available: https://designbuilder.co.uk/.

[23] "EnergyPlus," [Online]. Available: https://energyplus.net/. [Accessed 2019].

[24] D. La, Y. Dai, et al, "Case study and theoretical analysis of a solar driven two-stage rotary desiccant cooling system assisted by vapor compression air-conditioning," Solar Energy, vol. 85, no. 11, pp. 2997-3009, 2011.

[25] A. Pitts and J. Bin Saleh, "Transition spaces and thermal comfort-opportunities for optimising energy use," in 23rd Conference on Passive and Low Energy Architecture, 2013. 